\title{
Erratum to: Effect of neoadjuvant chemotherapy on tumor-infiltrating lymphocytes and PD-L1 expression in breast cancer and its clinical significance
}

Vasiliki Pelekanou ${ }^{1 *+}$, Daniel E. Carvajal-Hausdorf ${ }^{1 \dagger},{\text { Mehmet Altan², Brad Wasserman }{ }^{1} \text {, Cristobal Carvajal-Hausdorf }}^{2}$ Hallie Wimberly', Jason Brown', Donald Lannin ${ }^{3}$, Lajos Pusztai ${ }^{2}$ and David L. Rimm ${ }^{1,2}$

\section{Erratum}

The original article [1] has been updated. When originally published, the legends for Fig. 2 and Fig. 3 were in the wrong order, they have been switched back to the correct Figure.

\section{Author details}

'Department of Pathology, Yale University School of Medicine, 310 Cedar St, PO Box 208023, New Haven, CT 06520-8023, USA. ²Department of Medical Oncology, Yale University School of Medicine, New Haven, CT, USA.

${ }^{3}$ Department of Surgery, Yale University School of Medicine, New Haven, CT, USA.

Received: 22 August 2017 Accepted: 24 August 2017

Published online: 25 September 2017

\section{Reference}

1. Vasiliki P, Carvajal-Hausdorf DE, Mehmet A, Brad W, Cristobal C-H, Hallie W, Jason B, Donald L, Lajos P, Rimm DL. Effect of neoadjuvant chemotherapy on tumorinfiltrating lymphocytes and PD-L1 expression in breast cancer and its clinical significance. Breast Cancer Res. 2017;19:91. doi:10.1186/s13058-017-0884-8.

\footnotetext{
* Correspondence: vasiliki.pelekanou@yale.edu

${ }^{\dagger}$ Equal contributors

${ }^{1}$ Department of Pathology, Yale University School of Medicine, 310 Cedar St, PO Box 208023, New Haven, CT 06520-8023, USA
} 